\title{
Estimating High Mobility Group Box Protein 1 (HMGB1) Single Nucleotide Polymorphisms Among Hepatitis B Virus Infected Patients of Pakistan Origin
}

Sobia Tabassum ( $\nabla$ sobia.tabasum@iiu.edu.pk)

International Islamic University Pakistan

\section{Zanib Khalid}

International Islamic University

Zahra Zahid Piracha

International Islamic University

Umar Saeed

International Islamic University

Muhammad Ashraf

PAF-IAST: Pak-Austria Fachhochschule Institute of Applied Sciences and Technology

Hafsa Aziz

NORI Hospital ISlamabad

Short report

Keywords: HMGB1, HBV, SNP

Posted Date: April 30th, 2021

DOI: https://doi.org/10.21203/rs.3.rs-237334/v2

License: (a) (i) This work is licensed under a Creative Commons Attribution 4.0 International License.

Read Full License 


\section{Abstract}

HMGB1 is nuclear non-histone protein and unique member of cytokines. In viral hepatitis infection HMGB1 serum level increases and translocates towards cytoplasm and extracellular spaces where it activates single stimulating hepatic stellate cell proliferation which induces fibrogenic protein expression and causes hepatocellular carcinoma. In this study, total 150 subjects were recruited to assess the association between HMGB1 SNPs and HBV. Three types of genotypes were found visible in rs3742305 of HMGB1; wild type homozygous GG with $65 \%$, homozygous minor type CC with $6 \%$ and heterozygous minor type GC with $26 \%$ frequency distribution. High prevalence of GG genotype in the selected population presenting that GG genotype may have higher risk for susceptibility to HBV infection. Our results showed significant correlation of HMGB1 polymorphism with HBV infection in the selected Pakistani population.

\section{Introduction}

Hepatitis B virus may cause either acute or chronic liver infection. It may also involve in liver cirrhosis and hepatic-cellular carcinoma. Chronic infection with HBV is a major worldwide health problem despite the availability of vaccine (1). The HBV infection prevalence is highly changeable as estimated more than $10 \%$ in some Western Pacific countries and Asian's to under $0.5 \%$ in the northern European countries and United States. Globally the estimated HBV infected individuals are 350 million(2-4). Approximately 79 million carriers of HBV are found in Pakistan with an increase in carrier rate of 3-5 (5). The lifecycle of HBV has been studies exclusively however, the host factors involved in HBV replication and HBV associated HCC mechanisms are not fully understood.

The high mobility group (HMG) proteins binds to nucleosomes in non-sequence specific manner and have the ability to bring structural changes in chromatin (6). HMG proteins belonged to three families: HMGA, HMGB, and HMGN. These members are structurally divergent but share functional similarity (6). The most abundant protein of this family is HMGB (high-mobility group box) which is further divided into four groups (HMGB1, HMGB2, HMGB3 and HMGB4) (6). HMG-box family showcases diversity of characters including chromatin remodeling, transcription, replication, repair, recombination and genomic stability, moreover extracellular HMGB1 involves in cell growth and mitotic activity, receptor signaling(6). This emphasis that HMGB1 plays a critical role in the pathogenesis and treatment of liver diseases.

A single nucleotide polymorphism (SNP) is the stable replacement of single base in human gene. It is considered the most common genetic mutation in humans appearing in more than $1 \%$ of population. SNP is not identified as a disease-causing variant, but genetic variation may impact suggestively on the disease susceptibility (7). Common and rare SNPs and structural genomic changes may influence or restrict HCC development. Early identification of moderate to high genetic variants associated with HBVrelated HCC will help to determine susceptibility of infection better outcomes (8-10). For instance, mutational screening for BRCA1 and BRCA2 is used to identify women at risk for breast and ovarian cancer and is routinely used in accuracy of treatment protocols $(9-10)$. It is already a known fact that 
$\mathrm{HBV}$ infection is closely related with cytokines and polymorphisms of cytokine gene (ESR1) is reported to be associated with HBV infection (11-12). One of the SNP rs3742305 was identified in HMGB1 in HBV infected Chinese patients (14). Since there is no evidence of reported SNP in Pakistani population, identifying the association of HMGB1 and HBV. We first time reported the study based on polymorphism of HMGB1 gene in HBV patients identified in population of Pakistan origin.

\section{Materials And Methods}

\section{Patients Data}

In the current study, total 150 peoples were selected in which 100 patients with HBV infection (Acute, Chronic) were randomly selected from the Nuclear Medicine, Oncology and Radiotherapy Institute, Islamabad. Control sample size was 50 from normal population. Informed consent was obtained from all patients to participate in this study. All those patients were excluded from the study that was co-infected with HBV, HIV or patients infected with the alcoholic liver disease. $5 \mathrm{ml}$ blood samples from patients were collected along with singed consent forms. The diagnostic criteria for HBV infected patient were positive patients of HBsAg, $\mathrm{HBeAg}$ and anti- $\mathrm{HBc}$ and the patients have following symptoms of jaundice, fatty liver, abdominal pain and dark urine. Acute hepatitis $B(A H B)$, chronic hepatitis $B(C H B)$ and severe hepatitis $B(S H B)$ were selected. Patients having HBV were inducted with micro complications along with age, sex-matched, jaundice, fatty liver, abdominal pain, dark urine. HBV patients were assessed for AHB, $\mathrm{CHB}$ and SHB. The features/parameters recorded for the HBV patients are summarized in Table 1 and 2.

\section{DNA extraction method}

The leukocytes genomic DNA from $5 \mathrm{~mL}$ whole blood was isolated using organic phenol chloroform extraction method (15). DNA samples were diluted to $10 \mathrm{ng} / \mu \mathrm{L}$.

\section{Genetic Analysis}

SNP rs3742305 of HMGB1 was selected on the basis of previous findings (14), showing evidence of strong association of this SNP with HMGB1. Genotyping of allelic variant $(\mathrm{G}>\mathrm{C})$ for rs3742305 was done by PCR-RFLP method. All samples were amplified for target DNA fragment spanning rs3742305 region. The rs3742305 of HMGB1 gene was amplified by using specific pair of primers, sense (5'-3' GTCTCCTTTGCCCAGTGTATCTC) and anti-sense (5'-3' GTACACAGCCTTTGTCTGAGTCTG) designed by using premier primer 5 software.

\section{PCR amplification and Gel Electrophoresis}

PCR amplification was carried out with $26 \mu$ of master mix containing $8 \mu$ l of Go Taq, $6 \mu$ l of water, $1 \mu$ l of each forward and reverse primer and template with $10 \mu \mathrm{L}$ DNA was added. The reaction conditions were as follows $95 \circ \mathrm{C}$ for 5 minutes, $94 \circ \mathrm{C}$ for 1 minute $57 \circ \mathrm{C}$ for 1 minute and fifteen second and $72 \circ \mathrm{C}$ for 1 minute and thirty seconds with 40 cycles and $72 \circ \mathrm{C}$ for 7 minutes in elongation. Amplified product of $676 \mathrm{bp}$ was analyzed by electrophoresis on $2 \%$ agarose gel. 2 X TBE buffer was prepared from 10X TBE 
buffer solution and 2 grams of agarose was added to $100 \mathrm{ml}$ of 1 X TBE buffer solution. For visualization of DNA, $30 \mu$ of Ethidium Bromide was added to the gel solution. For comparing the fragment size, a 50 bp molecular marker was used (MBI Fermentas, Catalogue no SM1153). The gel was observed in gel DOC system. The PCR amplified product was digested with $\mathrm{BCl} /$ (recognition site T/GATCA) restriction enzyme at $56 \circ \mathrm{C}$ for 15 hours. The digested product was then analyzed by agarose gel and the required pattern of bands was obtained. $2 \%$ agarose gel solution was used for the separation of DNA fragments. A 50bp ladder was used to compare the band sizes (MBI Fermentas, Catalogue no SM1153).

\section{Statistical Analysis}

The mean, frequency and standard deviation was calculated by SPSS.16.0 statistical software (SPSS Inc. Chicago, IL, United States). Genotype, allelic frequency, P-value were calculated by Hardy -Weinberg frequency calculator. $\mathrm{P}<0.01$ considered in Hardy-Weinberg equilibrium was considered significant.

\section{Results}

It has been reported that HMGB1 genotypes for four SNPs, 2262G/A (rs1045411), 1177G/C (rs3742305), 3814C/G (rs2249825), and rs4540927 (16). In our study, we analyzed genotype distribution of GG, GC and $\mathrm{CC}$ by entering observed genotype values in the internet calculator of hardy Weinberg equilibrium. The analysis revealed that in Pakistani population we found polymorphism of rs3742305 in HMGB1 gene as represented in Table 3 and 4. Among $100 \mathrm{HBV}$ patients GG and CC was homozygous genotype and GC was heterozygous genotype. The GG genotype was found in $65(60.84 \%)$ of total HBV patients, GC genotypes in $26(34.32 \%)$ while CC frequency was lower than GG and GC and detected in $9(4.84 \%)$ as shown in Table 3. PCR-amplified product of rs3742305 having size length of $676 \mathrm{bp}$ is shown in figure 1.

Allelic frequency of $\mathrm{G}$ was shown to be $156(78 \%)$ and for C, 44(22\%) as shown in Table 4. In control individuals $\mathrm{GG}$ and $\mathrm{CC}$ was homozygous genotype and $\mathrm{GC}$ was heterozygous genotype. The GG genotype was found in $20(39.69 \%), G C$ in $23(46.62 \%)$ while CC frequency was lower than GG and GC and detected in $7(13.69 \%)$. Allelic frequency of $\mathrm{G}$ is $63 \%$ and $\mathrm{C}$ is $37 \%$.Chi square and $\mathrm{P}$-value calculated using Chi square and P-value calculator is 0.01 and degree of freedom is 2 . Three types of rs 3742305 genotypes in HBV infected patients, wild type homozygous GG, minor homozygous CC and minor heterozygous GC. Genotypic distribution of GG 65(60.84\%), GC 26(34.32\%) and CC 9(4.84\%). Allelic frequency of $G$ is $156(78 \%)$ and $C$ is $44(22 \%)$ and in control individuals $20(39.69 \%), 23(46.62 \%)$ and $7(13.69 \%)$ for GG, GC and CC respectively. Hardy-Weinberg equilibrium by chi square test showed that Pvalue is 0.01 , which confirmed that there is significant association between polymorphism of HMGB1 and HBV patients and studied group was in hardy-Weinberg equilibrium. Figure 2 shows the PCR RFLP assay, where the GC genotype shows band length of $676 \mathrm{bp}, 496 \mathrm{bp}$ and $180 \mathrm{bp}$ and GG shows band length of $676 \mathrm{bp}$ only. Frequency of three types of rs3742305 genotypes were compared in AHB, CHB and SHB patients (figure 3 ) and it was shown that GG genotype was most highest in all forms of hepatitis infection and highest in $\mathrm{CHB}$ patients as compared to GC and CC genotypes. Next we have compared the three types of rs3742305 genotypes in control and CHB patients (figure 4). It has been shown that only 
GG genotype is showing the significantly higher occurrence as compared to control but GC and CC genotypes show non-significant difference between control and $\mathrm{CHB}$ groups. Our data shows that HMGB1 1176 G/G genotype has progression towards HBV infection.

\section{Discussion}

HMGB1 is highly conserved non-histone nuclear DNA binding protein that contribute to architecture of chromatin DNA (6). It also acts as inflammatory cytokine in response to immune mediated diseases (17). In this study it is evident that most of the individuals of GG genotype having chronic hepatitis $B$ infection (CHB) were male. It means $\mathrm{CHB}$ infection has association with $\mathrm{GG}$ genotype and CC genotype is less prevalent in population. The most of polymorphism occurs in CHB patients while in SHB infected patients, very little polymorphism occur although SHB infected patients have acute-on-chronic liver failure with reduction in liver size. The fractions calculated reveal that in HMGB1 gene 1176 G/G genotype is more susceptible to $\mathrm{CHB}$ with more progressive status towards HBV infection and allele $\mathrm{G}$ is clearly related with infection production. The more persistence of $1176 \mathrm{G} / \mathrm{G}$ genotypes in HBV patients may leads to liver carcinoma results into liver failure and CHB progress towards SHB. The homozygous 1176 $\mathrm{C} / \mathrm{C}$ is less progressive then $1176 \mathrm{G} / \mathrm{G}$ while $1176 \mathrm{G} / \mathrm{C}$ have very little involvement in disease progression (14).

The uniqueness of this study is homozygous genotype which is involved in progression of disease. The homozygous GG genotype is associated with disease progression in HBV patients. In immune responses liver plays an important role. Parenchyma and non-parenchyma cells activate toll like receptors and Receptor for advanced glycation end-products. These receptors identify the HMGB1 in pathogenesis of liver disease (18-19) Extracellular HMGB1 have critical role in activation of hepatic injury depending upon receptors and post translational modification (14). It implicates in several immune-mediated diseases. About six polymorphism and four mutations were firstly identified and HMGB1 genotypes effect on the risks of SIRS and sepsis. Many researches reveal that polymorphism in HMGB1 leads to early and late death in individuals. Association between genetic variations and disease severity are also identified like polymorphism in HMGB1 leads to systemic inflammatory response syndrome (SIRS) (20). The tag SNPs in the entire gene involves in dysfunction syndrome (21). The 1176G/G genotype of HMGB1 gene associates with HBV infection leads towards disease elevation and current study confirmed this association and progress status similar to work of study.

\section{Conclusion}

In conclusion, our result shows that HMGB1 1176 G/G genotype has progression towards HBV infection and have high risks towards liver cirrhosis and hepatocellular carcinoma as compare to others as 1176 $\mathrm{C} / \mathrm{C}$ and $1176 \mathrm{G} / \mathrm{C}$ and it also represent that there is association of HMGB1 which is a proinflammatory mediator between $1176 \mathrm{G} / \mathrm{C}$ polymorphism of HMGB1 and hepatitis $\mathrm{B}$ virus infection. It shows the role of $\mathrm{HMGB} 1$ in pathophysiology of diseases related to HBV and in progression of HBV infection towards severity in the form of hepatocellular carcinoma. The future prospects of this study are that it provides a 
clue for researchers in finding the pathogenicity of HBV infection and finding of other restriction sites involve in causing of polymorphism association with HBV disease pathogenesis. It will help in risk assessment and prediction of clinical outcomes and provides a clue for diagnostics of acute and chronic hepatitis B. It will offer the counseling for precautions in life style changes to high-risk individual.

\section{List Of Abbreviations}

HMGB1

High Mobility Group Box Protein 1

WHO

World Health Organization

SNP

Single Nucleotide Polymorphisms

\section{Declaration}

Ethics approval and consent to participate:

The study has been approved by ethical review board of Islamic International University Islamabad.

Consent to publication:

All authors approved the submission of the manuscript for publication

Availability of data and material:

The data is available and can be used for the academic or research purposes.

\section{Competing interests:}

The authors have no conflict of interest.

\section{Funding:}

No funding was allotted for this study

\section{Authors Contribution:}

ST is principal investigator of the study. ZZP, US and ZK, wrote the manuscript and analyzed the data. ZZP and US improved the study. ZK performed experiments. MA, and HA assisted ST in providing technical support.

\section{Acknowledgements:}

Not applicable 


\section{References}

1. Wiegand J, Van Bömmel F, Berg T. (2010). Management of chronic hepatitis B: status and challenges beyond treatment guidelines, Semin Liver Dis. 30: 361-377.

2. Piracha ZZ, Kwon H, Saeed U, Kim J, Jung J, Chwae YJ, Park S, Shin HJ, Kim K. (2018). Sirtuin 2 Isoform 1 Enhances Hepatitis B Virus RNA Transcription and DNA Synthesis through the AKT/GSK-3 $\beta / \beta$ Catenin Signaling Pathway. J Virol. 92:e00955-18.

3. Saeed U, Kim J, Piracha ZZ, Kwon H, Jung J, Chwae YJ, Park S, Shin HJ, Kim K. (2019). Parvulin 14 and Parvulin 17 Bind to HBx and cccDNA and Upregulate Hepatitis B Virus Replication from cccDNA to Virion in an HBx-Dependent Manner. J Virol. 93:e01840-18.

4. Piracha ZZ, Saeed U, Kim J, Kwon H, Chwae YJ, Lee HW, Lim JH, Park S, Shin HJ, Kim K. An Alternatively Spliced Sirtuin 2 Isoform 5 Inhibits Hepatitis B Virus Replication from cccDNA by Repressing Epigenetic Modifications Made by Histone Lysine Methyltransferases. J Virol. 2020 Jul 30;94(16):e0092620. doi: 10.1128/JVI.00926-20.

5. Ali SA, Donahue RM, Qureshi H, Vermund SH. (2009). Hepatitis B and hepatitis C in Pakistan: Prevalence and risk factors. Int J Infect Dis. 13: 9-19.

6. Reeves R. (2010). Nuclear functions of the HMG proteins. BiochimBiophys Acta. 1799: 3-14.

7. Karlsen TH, Melum E, Franke A. (2010). The utility of genome-wide association studies in hepatology. Hepatology. 51:1833-1842.

8. Thomas DL, Thio CL, Martin MP, Qi Y, Ge D, O'Huigin C., et al. (2009). Genetic variation in IL28B and spontaneous clearance of hepatitis C virus. Nature. 461: 798-801.

9. Brennan P, Hainaut P, Boffetta P. (2011). Genetics of lung-cancer susceptibility. Lancet Oncol. 12: 399408.

10. Michailidou K, Beesley J, Lindstrom S, Canisius S, Dennis J, Lush MJ, et al. (2015). Genome-wide association analysis of more than 120,000 individuals identifies 15 new susceptibility loci for breast cancer. Nat Genet. 47: 373-380.

11. Yan Z, Tan S, Dan Y, Sun X, Deng G, Wang Y. (2012). Relationship between HLA-DP gene polymorphisms and clearance of chronic hepatitis $B$ virus infections: case-control study and metaanalysis. Infect Genet Evol. 12: 1222-1228.

12. Deng CQ, Deng GH, Wang YM. (2005). eNOS gene 894G/T polymorphisms among patients infected with HBV. VirologicaSinica. 20: 476-479 
14. Deng CQ, Deng GH, Wang YM. (2013). HMGB1 gene polymorphisms in patients with chronic hepatitis B virus infection. World J Gastroenterol. 19:5144-5149.

15. Köchl S, Niederstätter H, Parson W. (2005). DNA extraction and quantification of forensic samples using the phenol-chloroform method and real-time PCR. Methods Mol Biol. 297: 13-29.

16. Supic G, Kozomara R, Zeljic K, Stanimirovic D, Magic M, Surbatovic M, Jovic N, Magic Z. (2015). HMGB1 genetic polymorphisms in oral squamous cell carcinoma and oral lichen planus patients. Oral Dis. 21: 536-543.

17. Kaneko Y, Pappas C, Malapira T, Vale FL, Tajiri N, Borlongan CV. (2017). Extracellular HMGB1 modulates glutamate metabolism associated with kainic acid-induced epilepsy-like hyperactivity in primary rat neural cells. Cell PhysiolBiochem. 41: 947-959.

18. Chen R, Hou W, Zhang Q, Kang R, Fan XG, Tang D. (2013). Emerging role of high-mobility group box 1 (HMGB1) in liver diseases. Mol Med.19: 357-66.

19. Sopipong W, Tangkijvanich P, Payungporn S, Posuwan N, Poovorawan Y. (2011). The KIF1B (rs17401966) single nucleotide polymorphism is not associated with the development of HBV-related hepatocellular carcinoma in Thai patients. Asian Pac J Cancer Prev. 14: 2865-2869.

20. Kornblit B, Munthe-Fog L, Madsen HO, Strom J, Vindelov L, Garred P. (2008). Association of HMGB1 polymorphism with outcomes in patients with systemic inflammatory response syndrome. Crit Care. 12: 83.

21. Zeng L, Zhang AQ, Gu W, Chen KH, Jiang DP, Zhang LY, Du DY, Hu P, Huang SN, Wang HY, et al., (2011). Clinical relevance of single nucleotide polymorphisms of the high mobility group box 1 protein gene in patients with major trauma in southwest China. Surgery. 151:427-436.

\section{Tables}

Table 1: Mean values of different parameters of HBV 


\begin{tabular}{|c|c|}
\hline Characteristics & Mean \pm Standard deviation \\
\hline Age (Years) & $2.52 \pm 1.068$ \\
\hline Jaundice & $1.69 \pm 0.465$ \\
\hline Fatty liver & $1.29 \pm 0.465$ \\
\hline Abdominal pain & $1.33 \pm 0.473$ \\
\hline Dark urine & $1.45 \pm 0.500$ \\
\hline HBsAg & $1.02 \pm 0.141$ \\
\hline HBeAg & $1.05 \pm 0.219$ \\
\hline Anti HBC & $1.67 \pm 0.473$ \\
\hline Viral load & $3.217 \pm 2.183$ \\
\hline
\end{tabular}

Table 2: Demography and anthropometric parameters

\begin{tabular}{|c|c|c|}
\hline Parameters & $\begin{array}{c}\text { HBV } \\
\text { N=100 }\end{array}$ & Frequency (\%age) \\
\hline Male & 57 & $57 \%$ \\
\hline Female & 43 & $43 \%$ \\
\hline Married & 70 & $70 \%$ \\
\hline Un-married & 30 & $30 \%$ \\
\hline Family History & 12 & $12 \%$ \\
\hline AHB & 29 & $29 \%$ \\
\hline CHB & 54 & $54 \%$ \\
\hline SHB & 17 & $17 \%$ \\
\hline
\end{tabular}

Table 3: Genotype distribution of GG, GC and CC for rs3742305 in HBV 'atients and controls 


\begin{tabular}{|l|r|r|c|}
\hline \multicolumn{4}{|c|}{ Genotypes for rs3742305 } \\
\hline HBV (N=100 ) & GG & GC & CC \\
\cline { 2 - 4 } & 65 & 26 & 9 \\
\hline Expected H-W frequency & 60.84 & 34.32 & 4.84 \\
\cline { 2 - 4 } & $60.84 \%$ & $34.32 \%$ & 4.84 \\
\hline Controls (N=50 ) & & & \\
\cline { 2 - 4 } & & GG & CC \\
\hline Expected H-W frequency & 19.85 & 23.31 & 6.85 \\
\cline { 2 - 4 } & $39.69 \%$ & $46.62 \%$ & $13.69 \%$ \\
\hline
\end{tabular}

able 4: Allelic distribution of $\mathrm{G}$ and $\mathrm{C}$ for rs3742305in both patients and controls

\begin{tabular}{l|r|r|}
\hline \multicolumn{3}{|c|}{ Allelic frequency for rs3742305 } \\
\hline HBV(N=100) & G & C \\
\cline { 2 - 3 } & 156 & 44 \\
\hline Expected H-W frequency & $78 \%$ & $22 \%$ \\
\hline Controls (N=50) & G & C \\
\cline { 2 - 3 } & 63 & 37 \\
\hline Expected H-W frequency & $63 \%$ & $37 \%$ \\
\hline
\end{tabular}

Figures 


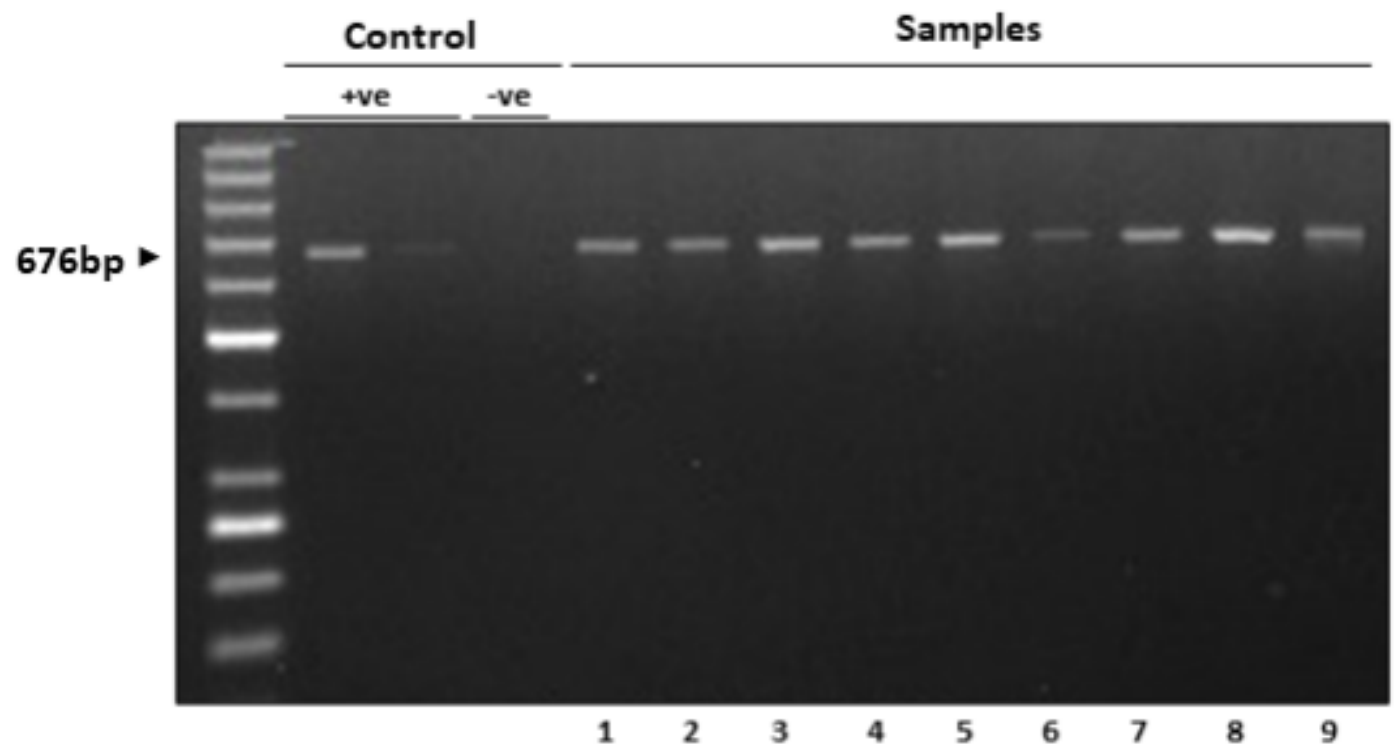

Figure 1

PCR-Amplified product of rs3742305: Lane M: 50bp, DNA ladder, Lane 1-9; Amplified product of rs3742305, NTC; Negative Control, +ve Cont: Positive Control

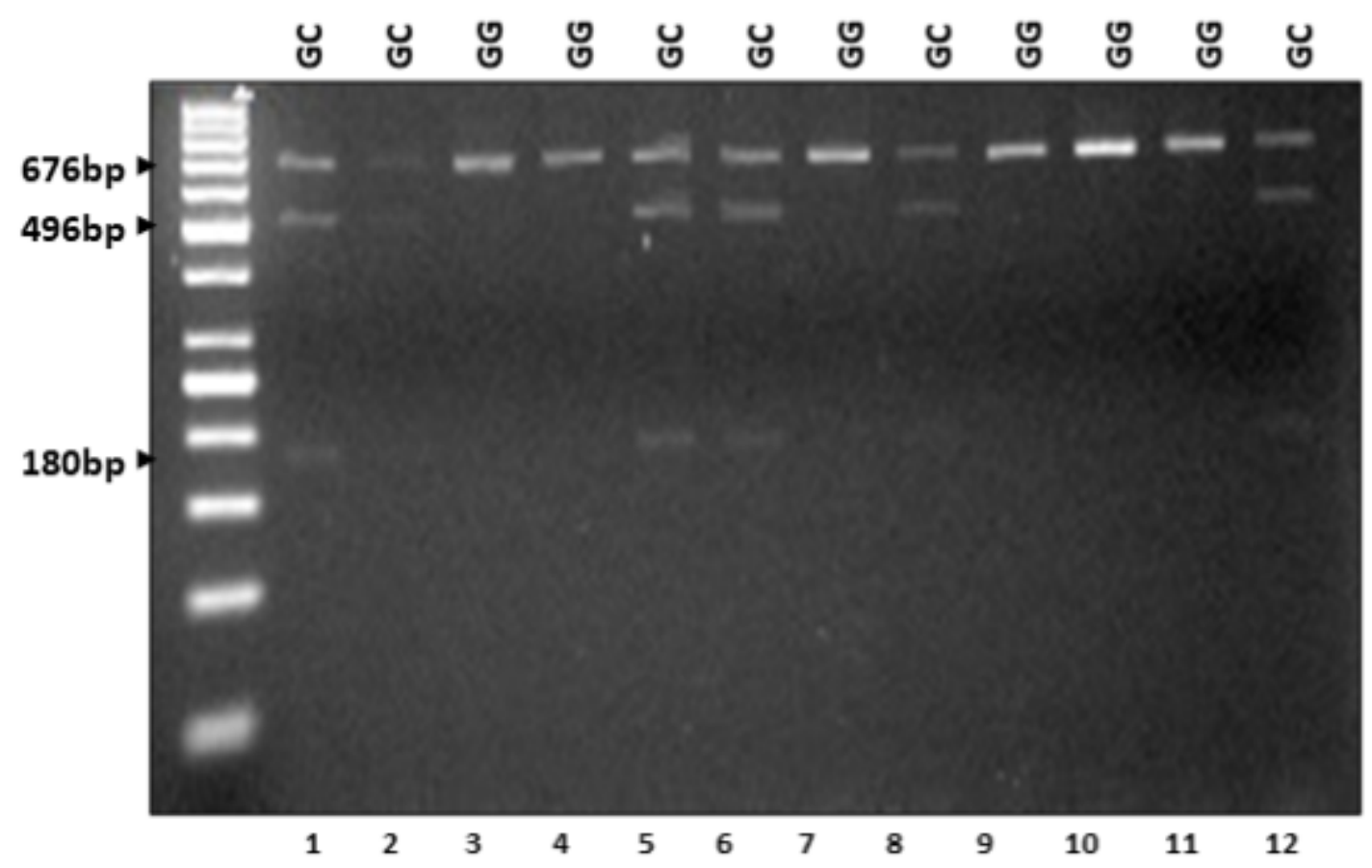

Figure 2

RFLP Analysis of rs3742305: Lane M: 50bp DNA ladder, GC genotype shows 676bp, 496bp and 180bp and GG shows 676bp. 


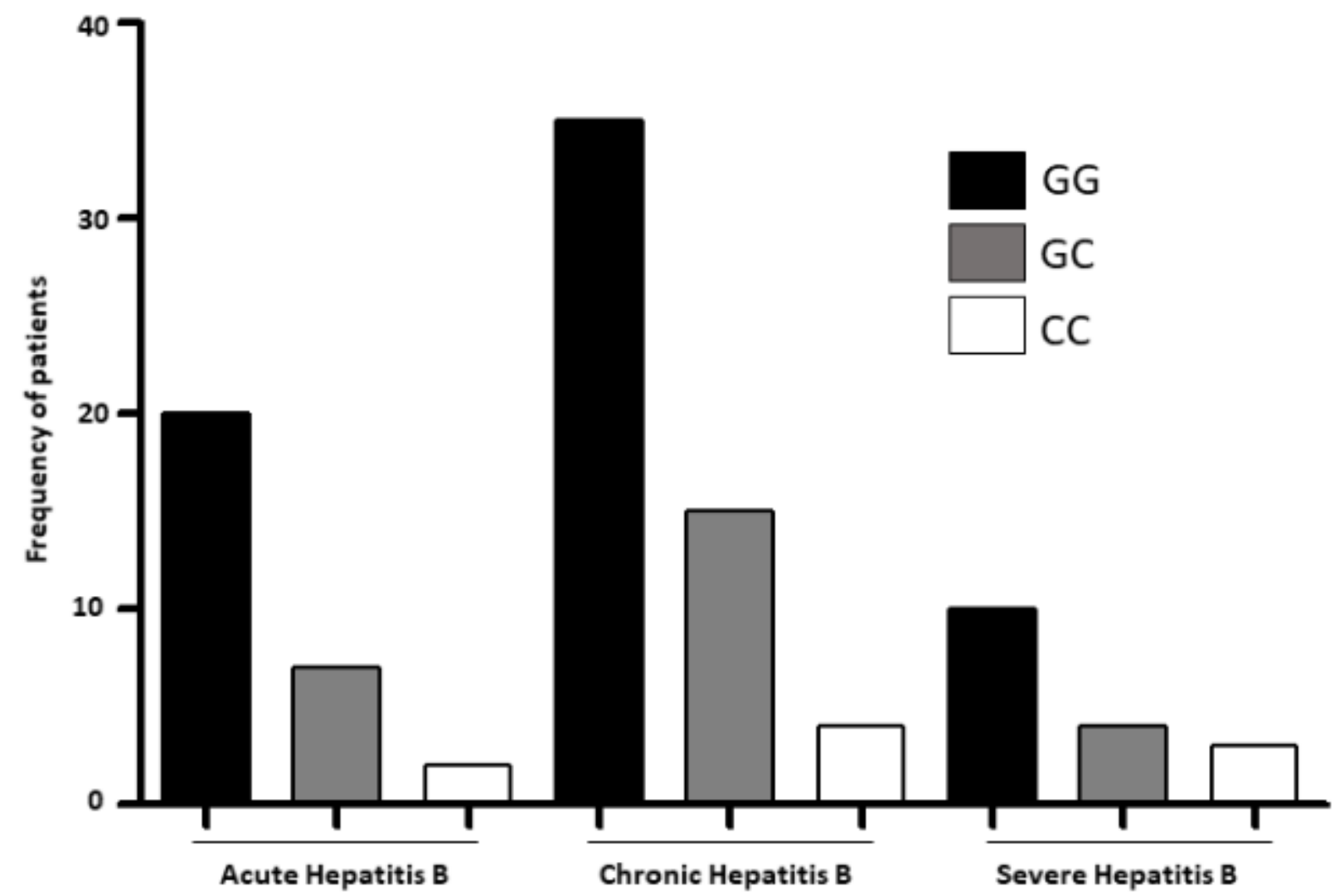

Figure 3

Comparison of three types of rs3742305 genotypes in AHB, CHB and SHB patients: black bar shows GG genotype, gray bar shows GC genotype and white bar shows CC 


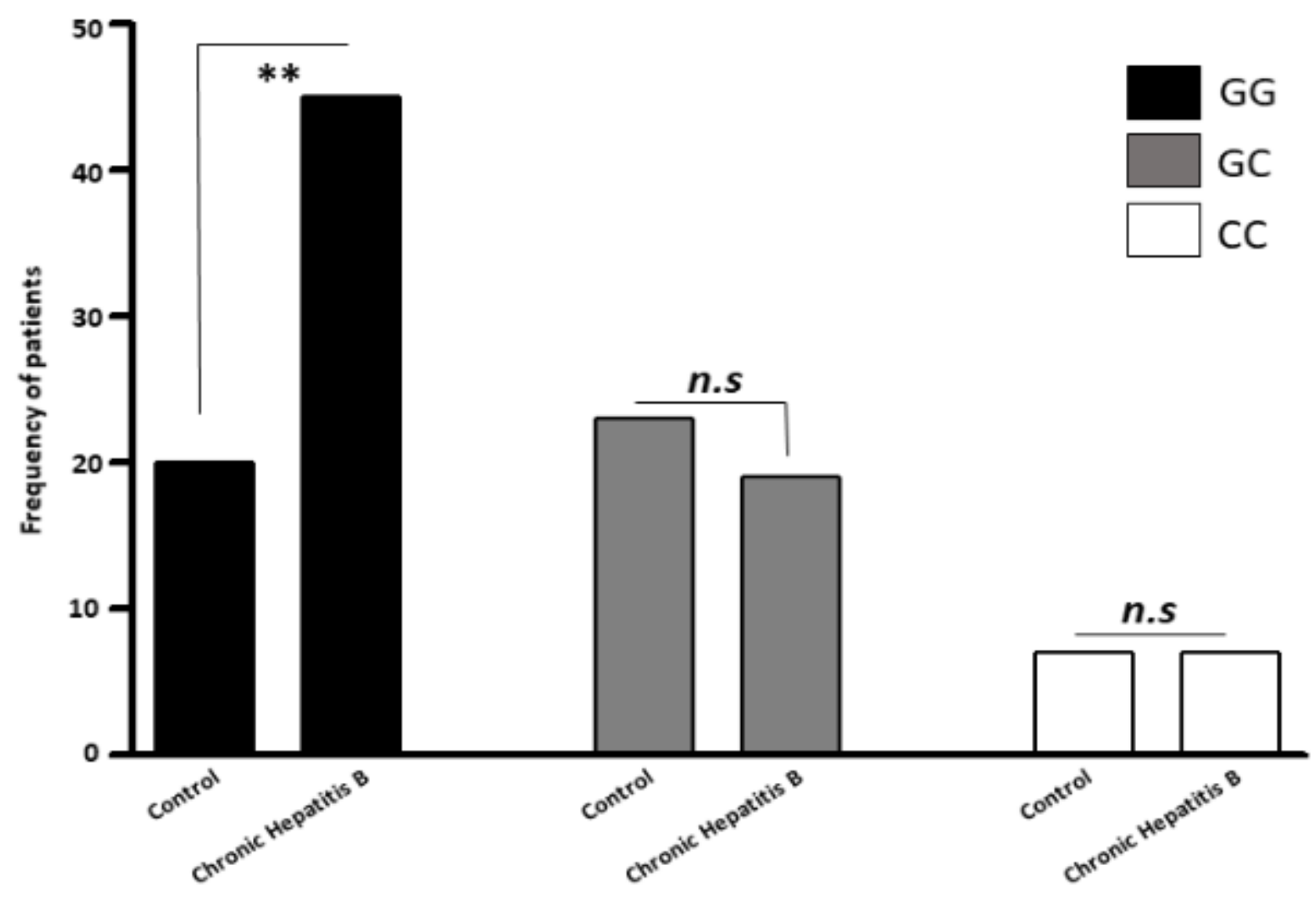

Figure 4

Comparison of three types of rs3742305 genotypes in control samples and CHB patients: black bar shows GG genotype, gray bar shows GC genotype and white bar shows CC genotype. 